\title{
Consumption and production waste: another externality of tobacco use
}

\author{
Thomas E Novotny, Feng Zhao
}

\begin{abstract}
Objective-To describe the waste produced by and environmental implications of individual cigarette consumption (filter tips, packages, and cartons) and tobacco manufacturing.

Study selection-All available articles and reports published since 1970 related to cigarette consumption and production waste were reviewed.
\end{abstract}

Data sources-Global cigarette consumption data were used to estimate cigarette butt and packaging waste quantities. Data from the Center for Marine Conservation's International Coastal Cleanup Project were used to describe some environmental impacts of tobacco-related trash. Data from the United States Environmental Protection Agency's (EPA's) Toxics Release Inventory and reported global cigarette consumption totals were used to estimate waste production from cigarette manufacturing.

Data extraction and synthesis-In 1995, an estimated 5.535 trillion cigarettes (27 675 million cartons and 276753 million packages) were sold by the tobacco industry globally. Some of the wastes from these products were properly deposited, but a large amount of tobacco consumption waste ends up in the environment. Some is recovered during environmental clean-up days. For the past eight years (1990-1997), cigarette butts have been the leading item found during the International Coastal Cleanup Project; they accounted for $19.1 \%$ of all items collected in 1997. The tobacco manufacturing process produces liquid, solid, and airborne waste. Among those wastes, some materials, including nicotine, are designated by the EPA as Toxics Release Inventory (TRI) chemicals. These are possible environmental health hazards. In 1995, the global tobacco industry produced an estimated 2262 million kilograms of manufacturing waste and 209 million kilograms of chemical waste. In addition, total nicotine waste produced in the manufacture of reduced nicotine cigarettes was estimated at 300 million kilograms.

Conclusions-Laws against littering relative to cigarette butts could be better enforced. Additional taxes might be levied on cigarette products that would then be directed to environmental clean-up efforts. The tobacco industry should improve the biodegradability of filters, reduce packaging waste, and educate its customers. Worksites and public buildings should be encouraged or required to supply appropriate disposal mechanisms at all building entrances. Public awareness campaigns about the magnitude and prevention of cigarette consumption waste could be developed through partnerships among environmental groups, health organisations, and environmental protection agencies. Tobacco production waste should be a source of concern and regulation by governments throughout the world; it contains numerous chemicals which may be considered health hazards, not the least of which is nicotine produced in the manufacture of low-nicotine cigarettes.

(Tobacco Control 1999;8:75-80)

Keywords: tobacco waste, litter, environmental impact

\section{Introduction}

Externalities are the costs or effects of a consumer behaviour that may not be borne by the consumer and hence may not be included in the price of the consumed good. ${ }^{1}$ For example, a commonly analysed externality of cigarette smoking is the economic cost of smoking-attributable medical care for smokers, which is borne by non-smokers and by governments as well as by the smoker. ${ }^{2}$ Another externality is the health effects of environmental tobacco smoke on non-smokers and on families of smokers. ${ }^{3}$ Finally, other environmental externalities include deforestation as a result of tobacco production (see pages 18-28 of this issue), pesticide use in tobacco agriculture, and fires caused by cigarette smoking. All these externalities affect the social costs of smoking, which may need to be addressed by policy actions of government or the private sector. Here we describe additional externalities of tobacco use involving waste production due to individual consumption as well as to the tobacco manufacturing process.

The waste products of cigarette consumption are clearly visible whenever one walks on a city sidewalk or uses a public beach. Cigarette butts, packages, cellophane wrappers, and cartons are ubiquitous forms of trash. Although 
Table 1 Estimates of total and filtered cigarette consumption, cartons, and packages produced in 49 selected countries and worldwide, 1995 (million units)

\begin{tabular}{|c|c|c|c|c|c|}
\hline Country & $\begin{array}{l}\text { Cigarette } \\
\text { consumption }\end{array}$ & $\begin{array}{l}\% \text { of } \\
\text { Filtered } \\
\text { cigarettes } \\
\text { (sales) }\end{array}$ & Cigarette filters & Cartons & Packages \\
\hline Argentina & 41000 & 98 & 40180 & 205 & 2050 \\
\hline Australia & 32179 & 95 & 30570 & 161 & 1609 \\
\hline Austria & 13192 & 99 & 13060 & 66 & 660 \\
\hline Bangladesh & 14450 & 14 & 2023 & 72 & 723 \\
\hline Belgium-Luxembourg & 16194 & 95.5 & 15465 & 81 & 810 \\
\hline Brazil & 1194000 & 99 & 118206 & 597 & 5970 \\
\hline Bulgaria & 16000 & 92.8 & 14848 & 80 & 800 \\
\hline Canada & 53500 & 97.5 & 52163 & 268 & 2675 \\
\hline Chile & 12561 & 99 & 12435 & 63 & 628 \\
\hline China & 1660250 & 72 & 1195380 & 8301 & 83013 \\
\hline Colombia & 19800 & 85.1 & 16850 & 99 & 990 \\
\hline Cuba & 15900 & 48.5 & 7712 & 80 & 795 \\
\hline \multicolumn{6}{|l|}{ Former } \\
\hline Czechoslovakia & 29150 & 95 & 27693 & 146 & 1458 \\
\hline Denmark & 8360 & 83.5 & 6981 & 42 & 418 \\
\hline Egypt & 38745 & 92.1 & 35684 & 194 & 1937 \\
\hline France & 88336 & 86.9 & 76764 & 442 & 4417 \\
\hline Former Soviet Union & 352550 & 74.9 & 264060 & 1763 & 17628 \\
\hline Germany & 149000 & 95.7 & 142593 & 745 & 7450 \\
\hline Greece & 30700 & 97.6 & 29963 & 154 & 1535 \\
\hline Hungary & 28850 & 96.4 & 27811 & 144 & 1443 \\
\hline India & 87430 & 64.5 & 56392 & 437 & 4372 \\
\hline Indonesia & 175810 & 69 & 121309 & 879 & 8791 \\
\hline Iran & 24000 & $81.11^{\star}$ & 19466 & 120 & 1200 \\
\hline Iraq & 13200 & $81.11^{\star}$ & 10707 & 66 & 660 \\
\hline Italy & 87750 & 94 & 82485 & 439 & 4388 \\
\hline Japan & 318177 & 99 & 314995 & 1591 & 15909 \\
\hline Malaysia & 16700 & 94.7 & 15815 & 84 & 835 \\
\hline Mexico & 46298 & 81.9 & 37918 & 231 & 2315 \\
\hline Morocco & 15526 & 55 & 8539 & 78 & 776 \\
\hline Netherlands & 25000 & 88.9 & 22225 & 125 & 1250 \\
\hline Nigeria & 18500 & 70 & 12950 & 93 & 925 \\
\hline Philippines & 62009 & 95.5 & 59219 & 310 & 3100 \\
\hline Poland & 103000 & 76.9 & 79207 & 515 & 5150 \\
\hline Portugal & 16247 & 97 & 15760 & 81 & 812 \\
\hline Romania & 39000 & 50 & 19500 & 195 & 1950 \\
\hline Saudi Arabia & 19850 & $81.11^{\star}$ & 16100 & 99 & 993 \\
\hline South Africa & 37695 & 92.1 & 34717 & 188 & 1885 \\
\hline South Korea & 93500 & 98 & 91,630 & 468 & 4675 \\
\hline Spain & 77980 & 97 & 75641 & 390 & 3899 \\
\hline Sweden & 8200 & 96 & 7872 & 41 & 410 \\
\hline Switzerland & 15550 & 99.3 & 15441 & 78 & 778 \\
\hline Taiwan & 37997 & 99 & 37617 & 190 & 1900 \\
\hline Thailand & 48600 & 97 & 47142 & 243 & 2430 \\
\hline Turkey & 96500 & 91.1 & 87912 & 483 & 4825 \\
\hline United Kingdom & 90970 & 99 & 90060 & 455 & 4549 \\
\hline United States & 470000 & 96.1 & 451670 & 2350 & 23500 \\
\hline Venezuela & 9653 & 98 & 9460 & 48 & 483 \\
\hline Yugoslavia & 45000 & $81.11^{\star}$ & 36500 & 225 & 2250 \\
\hline Subtotal & 4840259 & & 4008689 & 24201 & 242013 \\
\hline World & 5535059 & $82.82^{\star}$ & 4584136 & 27675 & 276753 \\
\hline
\end{tabular}

Source: National statistics/trade source/industry estimates/United States Department of Agriculture/World Tobacco

*Estimated percentages. World total is a weighted average using filtered cigarette consumption from all 49 countries with available data.

the paper and tobacco components are biodegradable, the filters and plastic wrappers are retained in the environment for long periods of time. Cigarette filters most commonly contain cellulose acetate, ${ }^{4}$ and some research has been undertaken by the tobacco industry to improve biodegradation of this material. ${ }^{5}$ Cellulose acetate filters may persist under normal environmental conditions for 18 months or more. ${ }^{6}$ Moreover, the butts themselves may be an acute health hazard to animals and to small children, who may eat them. ${ }^{7}$

Historically, the ocean has been a common dumping ground for human-made debris. Although cities can successfully treat sewage before environmental discharge, much of the marine debris from developed countries originates inland, even on city streets, where cigarette butts are dropped casually by the smoker, washed into storm sewers or drainage ditches, and out into larger waterways to the ocean. These items and the cigarette debris tossed directly onto beaches and other waterways have been subject to the Center for Marine Conservation (CMC) International Cleanup Project since $1990 .^{8}$

In addition, tobacco manufacturing produces chemical wastes, including nicotine, in the manufacture of cigarettes, cigars, smokeless tobacco, and other products. Many of these waste products are potential environmental hazards, and they are subject to careful regulation regarding disposal in most developed countries. The most hazardous chemicals released to the environment by all manufacturers, including the tobacco industry, in the United States are reported through the Toxics Release Inventory (TRI) each year. ${ }^{9}$

\section{Data sources}

Data on cigarette butts found in marine and other aquatic environments have been reported since 1990 by the CMC as part of the volunteer-based International Coastal Cleanup Project. ${ }^{8}$ The CMC is the leading advocacy group working in the United States on marine debris as an environmental issue. In addition, information on cigarette butts and packets collected on Clean Up Australia Day is available for $1993 .^{10}$ Total cigarette filter, packet, and carton waste production can be estimated by using World Health Organisation composite data sources on production, exports, imports, and per cent filter-tip cigarette consumption (personal communication via email, Emmanuel Guindon, World Health Organisation, August 1998).

A variety of publications report information on chemical wastes that are produced in tobacco manufacturing. The Statistical record of the environment ${ }^{9}$ reports chemicals in tobacco manufacturing waste in the United States that are treated onsite and offsite or are released into the environment. Operating and capital investment cost estimates for abatement of these wastes are available for 1988-1992. We also reviewed older reports providing information on tobacco manufacturing waste production and pollution control. ${ }^{11}{ }^{12}$ Finally, a single report, from Italy, describes how solid waste produced in manufacturing low-nicotine tobacco products contains high concentrations of nicotine. ${ }^{13}$

\section{Data extraction and synthesis}

CONSUMPTION WASTE

Worldwide, an estimated 5.535 trillion commercially manufactured cigarettes were consumed in 1995 (table 1). Specific estimates on filtered cigarette consumption for that year are available for 49 countries. ${ }^{14}$ These estimates were calculated as the number of units manufactured in the country, plus imports and minus exports; smuggling totals were excluded (globally, up to a third of annual exports are contraband, or smuggled ${ }^{15}$ ). Based on a weighted average of filtered cigarette consumption reported from the 49 countries, it was estimated that $83 \%$ of cigarettes consumed were filter-tipped. The number of packages (assumed average 20 cigarettes per package) 


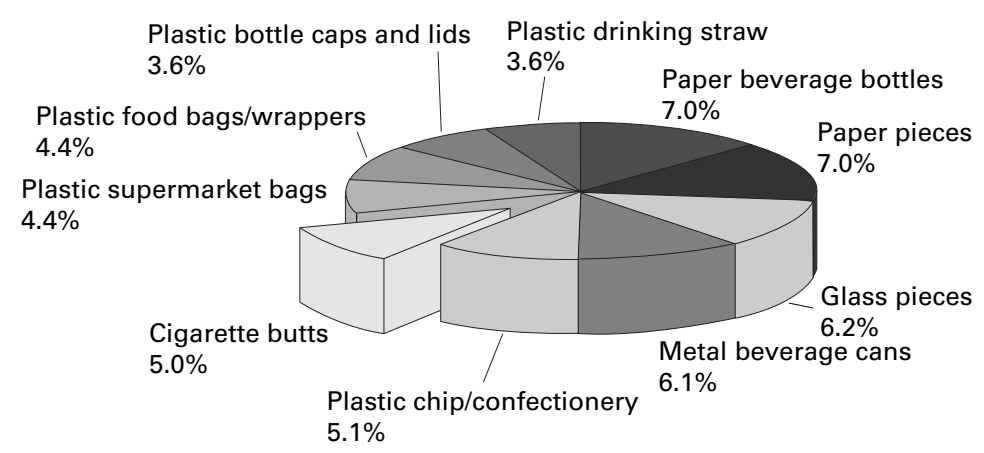

Figure 1 The 10 most common items of trash (52.4\% of total trash) collected on Australia Clean Up Day 1993. Source: Keep Australia Beautiful National Association.

produced globally was estimated at 276753 million, and the number of cartons (assumed average 10 packets per carton) was estimated at 27675 million. Table 1 does not include estimates for other packing materials, such as the corrugated paper boxes used to package cartons and the plastic wrappers used on some cigarette packages.

The data in table 1 represent the potential trash that may be produced globally by cigarette consumption. No data are available that may be used to quantify precisely the amount of trash deposited directly into the environment, but some countries, notably Australia, have attempted to describe the nature of trash collected from various sites, including waterways, roadways, parkland, public facilities, and so forth. ${ }^{10}$ Overall in Australia, cigarette butts comprised $5.0 \%$ (by absolute number) of all trash items collected on one clean-up day in 1993. They ranked sixth among all items collected (figure 1); in addition, cigarette packets and cartons were the most common individual paper items ("paper pieces" in the figure).

Since 1986, CMC volunteers around the world (90 countries in 1997) have participated in local clean-up efforts at approximately 5000 sites, including land-only, underwater, and shoreline sites. In 1997, 6185081 debris items were removed from these sites, and cigarette butts were the leading item among the top 20 items collected. Cigarette butts were almost three times as likely to be found as the next most frequent item, "plastic pieces." Overall, cigarette butts represented $19.1 \%$ of all items collected in 1997; since 1990, cigarette butts have represented at least $12 \%$ of total items collected (figure 2) (personal communication via email, Laurie Williams, Center for Marine Conservation, August 1998).

PRODUCTION WASTE

The tobacco manufacturing process produces liquid, solid, and airborne wastes. ${ }^{11}$ Liquid wastes include tobacco slurries, solvents, oils, and greases that originate in the manufacturing processes, building services, and facilities that may need special treatment or disposal. Solid wastes include paper, wood, plastics, unusable tobacco, packaging materials, and dirt that originate in the manufacturing process. These waste products are resold, recirculated, compacted, or put in landfills. Airborne wastes include non-toxic odours of manufacturing, in-plant dust, tobacco volatiles and particles, and other emissions. Abatement programmes for airborne waste include use of filters, dust collectors and scrubbers, low-sulphur fuels, and other controls.

Of greatest environmental concern among the manufacturing wastes are those chemicals ( $n=643$ ) specified as reportable to the TRI, developed by the United States Environmental Protection Agency (EPA) under the Emergency Planning and Community Right-toKnow Act of $1986 .{ }^{16}$ A waste is considered hazardous if it exhibits one or more of the following characteristics: ignitability (flammability), corrosivity (against metal), reactivity (capability of causing explosions, toxic fumes, gases, or vapours), or toxicity (harmful or fatal when ingested or absorbed). In the United States in 1992, the TRI reported in the Statistical record of the environment that tobacco manufacturing generated more than 27 million kilograms of production-related chemical waste, of which 2.2 million kilograms were TRI-treated or released into the environment. Overall, the tobacco industry ranked 18th among all industries in total chemical waste production. ${ }^{9}$

A 1970 study on solid waste management in the United States tobacco manufacturing industry estimated that in $1963,2700 \mathrm{~kg}$ of general solid waste were generated per manufacturing employee (total 225 million kilograms). ${ }^{12}$ We applied the estimated total chemical waste production for 1992 and the estimated solid waste production for 1963 to the number of cigarettes manufactured in those years to develop ratios of each waste to cigarettes produced. Adjusting these data for 1995 (the last year for which cigarette manufacturing data are available), we estimate that in the United States, 293 million kilograms of solid waste and 27 million kilograms of total chemical waste were produced (table 2). Globally, these totals are 2262 million kilograms for total solid wastes and 209 million kilograms for chemicals.

We also drew on an estimate of US $\$ 48$ million for the total 1992 abatement costs for TRI chemicals reported by the American tobacco manufacturing industry. ${ }^{9}$ Inflating these costs by the American consumer price index increase for 1992-1995 and cigarette production increases, $\$ 52$ million were spent in abatement for 1995; the global abatement cost estimate is $\$ 402$ million in that year (table 2 ).

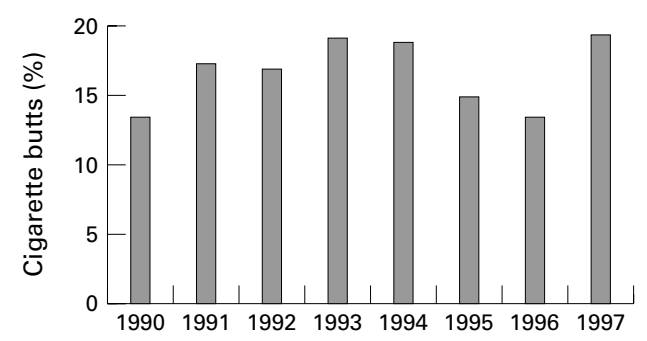

Figure 2 Percentage of cigarette butts among debris collected by International Beach Cleanup, 1990-1997. Source: Centre for Marine Conservation. 
Table 2 Estimated total tobacco production waste, chemical wastes, and Toxics Release Inventory chemical abatement costs, United States and global, 1995

\begin{tabular}{|c|c|c|c|c|}
\hline & $\begin{array}{l}\text { Cigarette } \\
\text { production * } \\
\text { (million pieces) }\end{array}$ & Total wastest $(\mathrm{kg})$ & $\begin{array}{l}\text { Total chemical } \\
\text { waste } \neq(\mathrm{kg})\end{array}$ & $\begin{array}{l}\text { Total cost for TRI } \\
\text { chemical } \\
\text { abatementS (US\$) }\end{array}$ \\
\hline United States & 716500 & $\begin{array}{l}292794224 \\
\text { (projected) }\end{array}$ & $\begin{array}{l}27008041 \\
\text { (projected) }\end{array}$ & $\begin{array}{l}52139701 \\
\text { (projected) }\end{array}$ \\
\hline Global & 5535059 & $\begin{array}{l}2261874818 \\
\text { (projected) }\end{array}$ & $\begin{array}{l}208640754 \\
\text { (projected) }\end{array}$ & $\begin{array}{l}402786213 \\
\text { (projected) }\end{array}$ \\
\hline
\end{tabular}

^Source: Table 1, United States Department of Agriculture.

† Source: United States Department of Health, Education, and Welfare: A study of solid waste management in the tobacco products industry, extrapolated to 1995 production levels for United States and World from table 1.

¥Source: Cummins 1970, inflated to 1995 production estimates from table 1 .

『Source: Statistical record of the environment 1995 (TRI chemicals only), costs inflated from 1992

by consumer price index increase from 1992 to 1995.

These estimates assume that all cigarette production processes around the world are similar and were unchanged with respect to waste production between 1963 and 1995 and that prices to control these wastes would increase at the same rate as the consumer price index. It may be that the price to control such waste has diminished with improved technology, but it may also be true that more stringent environmental controls, at least in industrial countries, may create higher costs of managing solid, liquid, and airborne wastes due to manufacturing.

The actual TRI chemicals reported by American manufacturers for 1996 (the last year for which data are reported) are shown in table 3. These include sources from cigarettes, cigars, smokeless tobacco, and other manufacturing sites. ${ }^{17}$ These wastes were treated onsite, treated offsite, or released into the environment. The total (3114221 kg) is almost a million kilograms higher than the TRI total reported in 1992 (table 2), but a significant portion of this difference may be accounted for by the inclusion of nicotine in the TRI. A discussion of the potential environmental impact of all these chemical releases is beyond the scope of this paper.

Nicotine is an interesting tobacco production waste product. The tobacco manufacturing process and all activities that use tobacco produce solid or liquid wastes with high concentrations of nicotine. ${ }^{13}$ Partly in response to information about the addictive nature of nicotine, ${ }^{18}{ }^{19}$ the market for low-nicotine cigarettes has been growing. Thus, an ironic outcome of this market growth is the increased need to detoxify nicotine in tobacco production waste. A non-recyclable, powdery,

Table 3 Releases to the environment of Toxics Release Inventory chemicals by tobacco manufacturing industry, United States, $1996^{*}$

\begin{tabular}{lr}
\hline Chemical & $\begin{array}{c}\text { Total quantity } \\
\text { released (kg) }\end{array}$ \\
\hline Ammonia & 946155 \\
Ethylene glycol & 8936 \\
Hydrochloric acid & 407371 \\
Hydrogen fluoride & 27937 \\
Methyl ethyl ketone & 340821 \\
Nicotine and nicotine salts & 900377 \\
Nitric acid & 58970 \\
Phosphoric acid & 6804 \\
Sulphuric acid & 67228 \\
Toluene & 349622
\end{tabular}

* Source: Right to Know database, 1996; includes air, water, land, underground injection, and offsite transfers. nicotine-containing waste is formed during tobacco production, which has average nicotine content of $18 \mathrm{~g}$ per $\mathrm{kg}$ of dry weight. This waste is classified as "toxic and hazardous" by European Union Regulations when the nicotine content exceeds $500 \mathrm{mg}$ per $\mathrm{kg}$ dry weight. According to a 1997 study from Italy, an average 3 million kilograms of this waste are reported in 1995 by the tobacco industry to be produced from 55300 million cigarettes manufactured in that country. ${ }^{13}$ If manufacturing processes and waste outputs per million cigarettes produced in the United States and globally are similar to those reported in Italy, it is estimated that $38870000 \mathrm{~kg}$ of nicotine waste was produced in the United States in 1995, and $300274000 \mathrm{~kg}$ was produced globally in the same year. Denicotinisation of waste requires chemical-physical treatments or biological methods with microorganisms to reduce the nicotine content of released wastes below the threshold of $500 \mathrm{mg}$ per $\mathrm{kg}$. In the United States, nicotine has been included on the TRI list since November $1994 .{ }^{20}$ Nicotine itself is an anti-parasitic plant pesticide.

\section{Conclusions and recommendations}

The health consequences of cigarette smoking to smokers and exposed non-smokers are well known. Cigarette products and production may also affect environments in other ways that require attention from environmental groups, industry, and government. Cellulose acetate filters from cigarette butts do not rapidly biodegrade; thus, they are a relatively long-lasting environmental problem, especially in waterways and run-offs from urban environments. At least 4.5 trillion filter-tipped cigarettes are deposited annually somewhere in the world. Many will find their way into appropriate disposal facilities, but the CMC clean-up data suggest that a large number end up on beaches and in other aquatic environments.

Smokers may not consider that a cigarette butt is litter, but these waste products seem to be ubiquitous. Perhaps because of the proliferation of restrictions on smoking in worksites and public places, it is common for building entrances to have a collection of cigarette butts nearby. These collections come in large part from smokers discarding cigarettes before they enter the building and from workers smoking on breaks. Some worksites have made special attempts to provide appropriate disposal facilities (figure 3 ).

Nevertheless, cigarette butts are frequently a source of urban blight and environmental pollution. In addition to the environmental contamination by cigarette butts, consumption waste left in ashtrays in the homes of smokers may be a source of poisoning for young children. In 1994-1996, the Rhode Island Department of Health identified 40 cases of cigarette butt ingestion among children aged 6 to 24 months as reported by the poison-control system in that state. ${ }^{7}$ Thirteen of the cases of ingestion produced symptoms such as vomiting, gagging, and lethargy. 


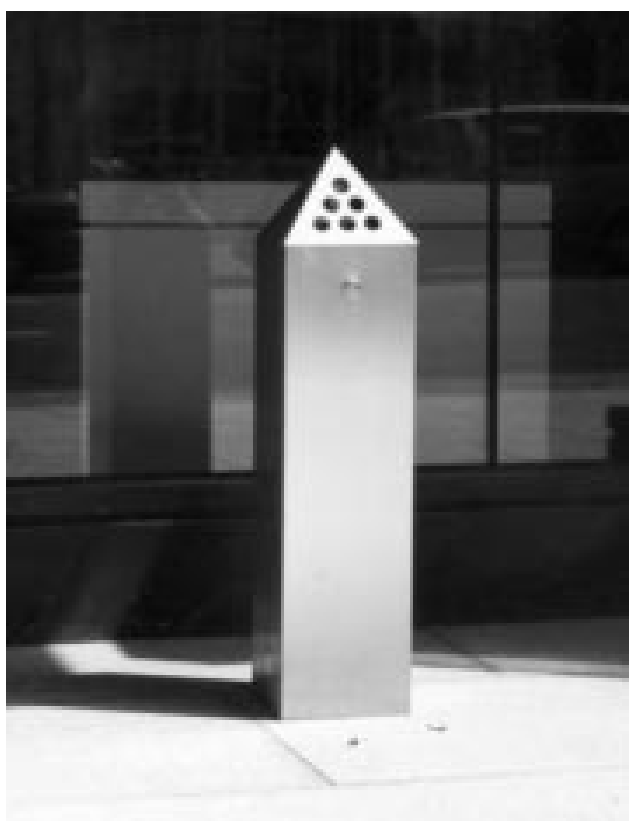

Figure 3 Cigarette disposal container outside offices in Washington, DC, USA. Worksite smoking bans have increased the problem of cigarette butts littering building entrances.

The cigarette butt problem may be mitigated through several channels other than general tobacco control efforts. First, laws against littering could be better enforced relative to cigarette butts. Second, additional taxes could be levied on cigarette products that could be directed to environmental clean-up efforts for consumption and production waste. Third, the tobacco industry should improve the biodegradability of filters, reduce packaging waste, educate its customers about their responsibility to the environment, and strive to responsibly manage production waste in developing countries as well as developed countries. Fourth, administrators of worksites and public buildings should be encouraged or required to supply appropriate disposal mechanisms at all building entrances (this might even be cost-effective in terms of public image, janitorial costs, and fire prevention) (figure 3). Fifth, increased public awareness campaigns about the magnitude and prevention of tobacco consumption and production waste could be developed through partnerships between environmental groups, health organisations, and environmental protection agencies.

Tobacco manufacturers, like other manufacturers in the United States and in other developed countries, generate several toxic chemicals as production waste. The EPA and other similar organisations in developed countries help assure that industry reports and manages such waste. However, it is not known what abatement procedures are being used in developing countries, where cigarette production capacity has rapidly increased in recent years. To meet the demands of emerging markets, it is likely that cigarette manufacturers will gravitate towards manufacturing venues where regulation is less stringent. In the absence of public awareness and governmental regulations, tobacco manufacturers may not address the problem of significant solid, liquid, airborne, and chemically toxic waste produced in cigarette manufacturing. Thus, it may be prudent for multinational health, trade, and economic agencies to raise environmental considerations related to tobacco production as a global health issue.

Additional research is needed to quantify the environmental impact of both tobacco consumption and production waste. Tobacco is a hazardous product when used as directed, but there is also a hazard due to production and consumption waste deposited into the environment. Perhaps the tobacco industry should be held partly accountable for the environmental clean-up costs related to cigarette butts and totally responsible for abatement of hazardous wastes resulting from the manufacturing process. It has been increasingly held accountable for the medical care costs associated with treating tobacco-attributable illnesses. This accountability should extend beyond the provision of cigarette butt disposal devices to smokers, which is primarily a public relations gimmick. It should also extend beyond the borders of developed countries, where regulatory controls on manufacturing waste may actually be enforced, to developing countries, which are increasingly at risk for environmental contamination as cigarette production capacity in those countries expands.

The authors would like to thank members of Globalink, who provided valuable information used in this report, as well as Laurie Williams of the Center for Marine Conservation for providing data from the Coastal Cleanup Project and Emmanuel Guindon of the World Health Organisation for providing data on cigarette consumption. The opinions expressed are solely those of the authors and do not represent official positions of the those of the authors and do not represent official positions of the the Johns Hopkins University.

1 Jacobs P. The economics of health and medical care, 2 nd ed. Rockville, Maryland: Aspen, 1987.

2 Miller LS, Zhang X, Novotny T, et al. State estimates of Medicaid expenditures attributable to cigarette smokingUnited States, fiscal year 1993. Public Health Rep 1998;113:140-51

3 US Environmental Protection Agency. Respiratory health effects of passive smoking: lung cancer and other disorders. Washington, DC: Office of Health and Environmental Assessment, 1992. (Publication No EPA/600/6-90/006F.)

4 US Department of Health and Human Services, Reducing the health consequences of smoking: 25 years of progress. A report of the Surgeon General, 1989. Rockville, Maryland: Public Health Service, Centers for Disease Control, Office on Smoking and Health, 1989. (DHHS Publication No

5 Collazo H, Haynes SK, McDonough MM. The mechanisms of degradation of cellulose acetate in the environment. Abstract No 5021, Tobacco Chemists' Research Conference, 1996.

6 Ach A. Biodegradable plastics based on cellulose acetate. $\mathcal{F}$ Macromol Sci Pure Appl Chem 1993;A30:733-40.

7 US Centers for Disease Control and Prevention. Ingestion of cigarettes and cigarette butts by children-Rhode Island, January 1994-July 1996. MMWR 1997;46:125-8.

8 Center for Marine Conservation. 1996 international coastal cleanup results. Washington, DC: Center for Marine Conservation, 1997 .

9 Dorgan CA. Statistical record of the environment, 3rd ed. New York: Gale Research Inc., 1995.

10 Clean Up Australia. Cleaning up Australia. Report on Clean Up Australia activities 1993. Clean Up Australia: Canberra, Australia, 1994

11 US National Industrial Pollution Control Council. The tobacco industry and pollution, sub-council report. Washington DC: US Government Printing Office, 1972. (Publication No $483-135 / 6$.

12 Cummins RL. A study of solid waste management in the tobacco products industry. In: $A$ division of technical operations open-file progress report (T05.4/0). Washington, DC: US Department of Health, Education, and Welfare, Public Health Service Environmental Health Service, Bureau of Solid Waste Management, 1970

13 Civilini M, Domenis C, Sebastianutto N, et al. Nicotine decontamination of tobacco agro-industrial waste and its 
degradation by micro-organisms. Waste Manage Res 1997; 15:349-58

14 Market Tracking International Ltd. World tobacco file, 1996, vol 2. London: International Trade Publications Ltd, 1996

15 Joosens L, Raw M. Cigarette smuggling in Europe: who really benefits? Tobacco Control 1998;7:66-71.

16 US Environmental Protection Agency. RCRA: reducing risk from waste. Washington, DC: EPA, September 1997. (EPA 530-K-97-004.)

17 Anon. <www.rtk.net> Right-to-Know network: EPA TRIS database. OMB Watch and Unison Institute, Washington DC, 15 December 1998.

18 US Department of Health and Human Services. The health consequences of smoking: nicotine addiction. A report of the
Surgeon General, 1988. Rockville, Maryland: Public Health Service, Centers for Disease Control, Office on Smoking and Health, 1988. (DHHS Publication No (CDC) 88-8406.)

19 US Department of Health and Human Services. The health consequences of smoking: the changing cigarette. A report of the Surgeon General, 1981. Rockville, Maryland: Public Health Service, Office of the Assistant Secretary for Health, Office on Smoking and Health, 1981. (DHHS Publication No (PHS) 81-50156.)

20 US Environmental Protection Agency. Emergency planning and community right-to-know section 313: list of toxic chemicals. Washington, DC: EPA, September 1996. (EPA 745-B-96-001.)

\section{Waste not, want not}

Reconstituted tobacco, known as "sheet" in the cigarette industry, is a major ingredient in modern cigarettes. It is manufactured from the recycled stems, stalks, scrap, collected dust, and floor sweepings from tobacco manufacturing plants. Various patents have been awarded to tobacco manufacturers for processing waste such as this into sheet. The ground-up materials are denicotinised, and chemicals, fillers, glue, and other agents are added to the slurry. The sheet is then pressed out and puffed, renicotinised, and ground into tiny curls before being incorporated into cigarettes. The waste constituents use in this process are imported and exported, depending on economic conditions. In 1995, $1135755 \mathrm{~kg}$ of tobacco stems and refuse were imported and $1989786 \mathrm{~kg}$ were exported by the United States.

Source: US import and exports history database, US Department of Commerce.

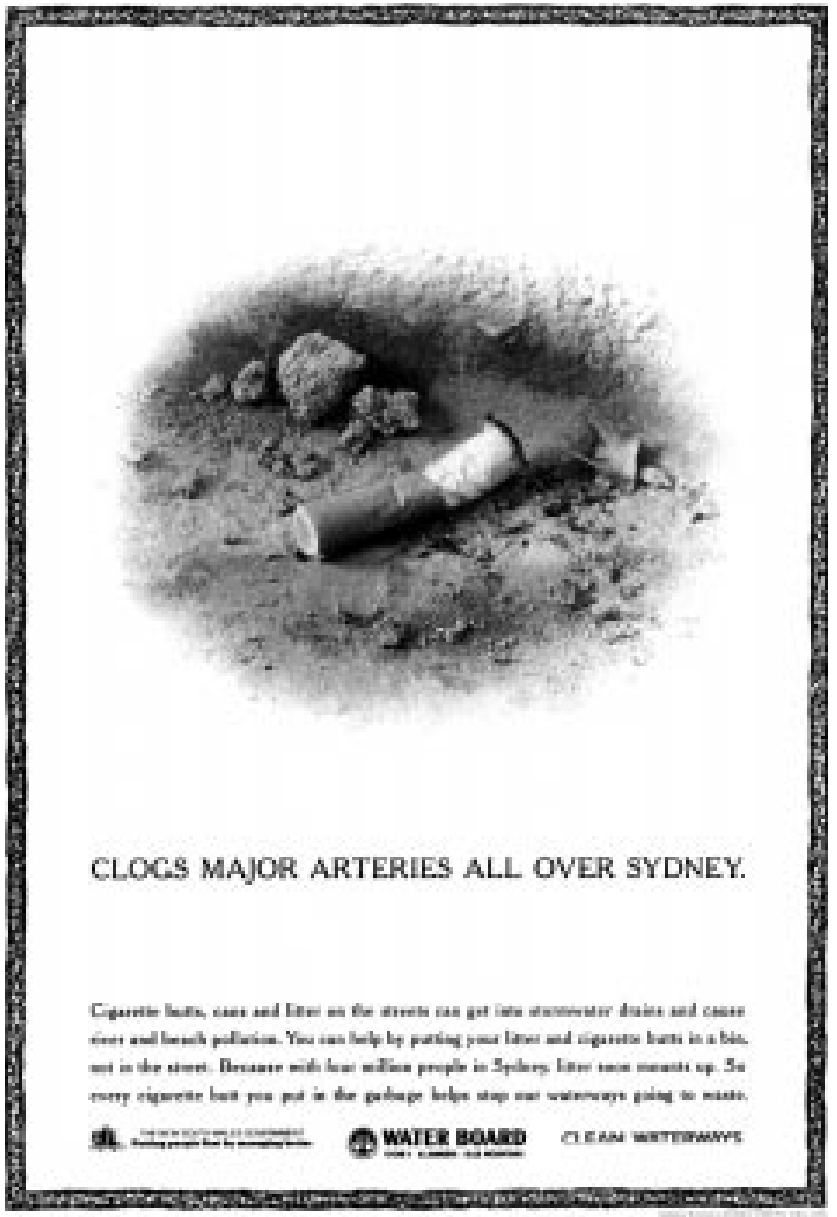

Australian anti-litter advertisement promoted in 1996 by the New South Wales government, the Sydney Water Board, and the Clean Waterways organisation. 